\title{
C-Reactive Protein - A Predictable Biomarker in Ischemic Stroke
}

\author{
MARIA TOTAN ${ }^{1,2}$, ELISABETA ANTONESCU1,3, MARIA GABRIELA CATANA ${ }^{1,3 *}$, MARIA MIHAELA CERNUSCA MITARIU ${ }^{1,3}$, \\ LAVINIA DUICA ${ }^{1}$, CORINA ROMAN FILIP1,3, RALUCA MONICA COMANEANU ${ }^{4}$, SEBASTIAN IOAN CERNUSCA MITARIU1,3 \\ ${ }^{1}$ Lucian Blaga University of Sibiu, Faculty of Medicine, 2A Lucian Blaga Str., 550169, Sibiu, Romania \\ ${ }^{2}$ Clinical Pediatric Hospital, Clinical Laboratory, 2-4 Pompeiu Onofreiu Str. 550166 Sibiu, Romania \\ ${ }^{3}$ County Clinical Emergency Hospital, 2-4 Corneliu Coposu Str., 550245, Sibiu, Romania \\ ${ }^{4}$ Titu Maiorescu University of Bucharest, Faculty of Dental Medicine, 67A Gh. Petrascu Str., 031593, Bucharest, Romania
}

\begin{abstract}
C-reactive protein (CRP) is a non-specific inflammatory marker, correlated with the severity and prognosis of ischemic stroke. We performed a retrospective study in which were included 81 patients diagnosed with acute ischemic stroke admitted between January and July 2017 in the Department of Neurology, Sibiu Emergency Clinical Hospital. CRP values were classified on three levels $(0-5 \mathrm{mg} / \mathrm{L}, 5-50 \mathrm{mg} / \mathrm{L}$ and $>50$ $\mathrm{mg} / \mathrm{L}$ ). We examined the correlation between CRP levels according to the type of ischemic (lacunar / territorial) stroke, the degree of motor deficit (quantified by the $m R C$ scale), the associated risk factors and the mortality rate. $P C R$ values above $50 \mathrm{mg} / L$ were found in patients with territorial stroke (15\%). Moderate motor deficits predominate, with $P C R$ values ranging from $5-50 \mathrm{mg} / \mathrm{L}$. The most important risk factors found in the patients included in our study were hypertension and atherosclerosis. We made correlations between these risk factors and the $P C R$ values. In most cases with these two risk factors were recorded a mean $P C R$ value $(5-50 \mathrm{mg} / \mathrm{L})$. For atherosclerosis the results were statistically significant, $p=0.021$. Most patients $(56 \%)$ had CRP levels ranging from 5 to $50 \mathrm{mg} / \mathrm{L}$. These values recorded highest death rates. $P C R$ it is an important marker of inflammation and it is important to be determined in all patients with acute ischemic stroke, especially which is thought to be correlated with the prognosis of these patients.
\end{abstract}

Keywords: C-reactive protein, inflammation, ischemic stroke.

Stroke is the third leading cause of death in industrialized countries ( $9 \%$ of all deaths) and one of the biggest causes of disability worldwide [1].

Ischemic stroke can have multiple etiologies characterized by the rule of the quarter: $25 \%$ cardioembolic causes, $25 \%$ - atherosclerotic causes (large cerebral vascular disease), 25\% - lacunae (affecting small cerebral vessels) and 25\% -unknown causes (cryptogenic cerebral vascular disease) [2].

High blood pressure, a major global problem, is the second risk factor, after age, which can lead to stroke. This risk factor can be controlled using an effective method of treating hypertension: a combined therapy with calcium channel blockers, angiotensin II and diuretics (modified oral dosage formulas containing one or more antihypertensive active substances are considered to be more effective), reducing the risk of stroke [3]. A multitude of recent studies demonstrate a close link between inflammation and a cerebrovascular event - ischemic stroke. There are five main ideas that support this statement [4]:

1. Firstly, studies indicate that inflammation plays an important role in all stages of atherogenesis. As a result of numerous stressors (smoking, angiotensin 2), the vascular endothelium exhibits selective adhesion of molecules, namely, vascular cell adhesion proteins (VCAM1) that bind to leukocytes [5]. Simultaneously, macrophages, as a result of the action of monocyte chemotactic protein 1, differentiate into macrophages M1 that are proinflammatory, resulting in the release of cytokines. Cytokines stimulate the migration of muscle cells from adventitia to intima and media, thus forming the fibrous plaque of the athermanous plaque.

2. The second line of evidence is based on multiple studies that have shown the link between the risk of recurrence of stroke and inflammatory markers - IL-6, PCR, which play an important role in the formation of the athermanous plaque.

3. Genetic studies reinforce the link between inflammation and recurrence of ischemic strokes. Alleviating aberrations in alleles that decode cytokines IL 1 and IL6 [6,7] were observed in $25 \%$ of patients with recurrence of ischemic stroke included in the Genetics study in stroke.

4. PET-CT supports and demonstrates the inflammationischemia relationship by revealing pro-inflammatory macrophages in the atherosclerotic plaque (18fluorodeoxyglucose capture is directly proportional to the number of macrophages present in the atheroma plate) [8-10].

5. At the same time, the correlation between inflammation and stroke is supported by the Oxford Plaque study, which examined 526 atherosclerotic plaques (endarterectomy made in symptomatic patients), highlighting the presence of significant inflammation in the symptomatic carotid artery in $2 / 3$ of the study participants [11].

Nowadays, there is a growing awareness of the incriminating role of the inflammatory mechanism in the onset and prognosis of ischemic stroke. The effects of inflammation causing cerebral damage and neurological consequences can be observed by imaging examination: MRI, CT or AngioCT [12].

Also, two other examinations that should become mandatory in exploring the hypertensive patient to avoid a stroke are echocardiography and carotid duplex ultrasound, with the proviso that ultrasound exposure may sometimes produce mild changes in physiological blood parameters [13].

It is known both experimentally and clinically that the cerebral response to ischemic injury is an acute inflammatory process characterized by rapid cellular 
activation with the secretion of proinflammatory mediators and infiltration with different inflammatory cells in the ischemic brain tissue (neutrophils, T cell subtypes, monocytes and macrophages).

Activation of TRL2 and TRL3 (TollLike Receptor) is the trigger for initiating the post-ischemic inflammatory process. TRL ligands are synthesized by ischemic focal cells and they activate macrophage infiltration and inflammatory cytokine secretion. Some cytokines produced by Thelper cells are neurotoxic (interleukins IL23, IL17) others have neuroprotective role (IL4, IL10) [8] .

Interaction between cellular immune system and inflammatory markers produces so-called SIDS (Stroke Immunodepression Syndrome). It has been observed that IL4, IL10, Treg (regulatory T cells) and TGF- $\beta$ (platelet growth factor) contribute to the immunodepression process, and IL17, IL23, with a differentiating T cells role, induce the initiation of the inflammatory process $[8,14]$ Biomarkers such as PCR, fibrinogen, ESR are considered predictable for the production, classification, severity and prognosis of ischemic stroke, their monitoring having an important role in prevention and treatment $[5,15]$.

Elevated serum levels of these reagents, especially the PCR level, have a prognostic role for cerebrovascular mortality. High serum levels of these markers accompany a number of other conditions that are associated with inflammation: infections, infarcts, trauma, autoimmune disorders, neoplasia [11, 16-19].

PCR is an acute phase reactant, being a sensitive indicator of inflammation and its dosing remains one of the most commonly used in current medical practice. It is produced rapidly in the liver following a tissue lesion, reaching a maximum level in $48 \mathrm{~h}$, and then decreases rapidly. In healthy people the mean value is about $1 \mathrm{mg} / \mathrm{l}$; in patients with acute stroke, with or without associated infection, there is a rapid increase (in the first three hours) up to 100 times higher. After an ischemic attack, an increase in the level of PCR was observed in $75 \%$ of patients [11].

Status epilepticus (SE) and seizure clusters (SCs) are emergency situations, which require immediate and effective treatment [20]. Recent data have shown that seizures may be a consequence of misguided inflammatory response and blood-brain barrier disruption. Both peripheral and brain proinflammatory events have been demonstrated to govern the onset of status epilepticus and it was demonstrated that the median time needed to control the refractory SE is significantly shorter with VPA (5 $\mathrm{min}$ ) then diazepam (17 $\mathrm{min})[20,21]$ and also the relative ease of administration, lack of serious side effects and the pharmacokinetic profile, make IV LEV an attractive alternative in the management of SE as second line therapy. As a result, methods to pharmacologically reduce bloodbrain barrier permeability and inflammation reduction have emerged as means to reduce seizure burden but this must be assessed in large group studies to obtain more relevant data [20].

\section{Experimental part}

A retrospective study was performed on a batch of 81 patients diagnosed with acute ischemic stroke and PCR monitoring, but without other biologically modified samples suggestive for various infections or dehydration, hospitalized in the Department of Neurology at County Emergency Clinical Hospital, Sibiu, between J anuary and July 2017.

The PCR results from the hospital's electronic archive were used to perform the study. Another criterion for inclusion of the patients in the study, besides the recording of the PCR values, was represented by the results of the paraclinical imaging examinations, namely CT / MRI. All patients with modified acute phase reactants (ESR, fibrinogen, leukocytes) and fever, suggesting the existence of an infection on the basis, were excluded. Therefore, after evaluating and fulfilling this criterion, patients who did not have imaging signs of acute cerebral infarction were excluded.

In the study were included data about genre, the type of stroke - ischemic, lacunar or territorial, PCR value, comorbidities such as HT (hypertension), AF (atrial fibrillation), atherosclerosis, diabetes mellitus, hyperlipidemia, mRC scale (motor deficit).

The statistical analysis of the data was done using the SPSS 20 program.

\section{Results and discussions}

The data were classified into 3 categories according to the CPR biomarker value: normal CPR values $(0-5 \mathrm{mg} / \mathrm{L})$, values ranging from $5-50 \mathrm{mg} / \mathrm{L}$ to values above $50 \mathrm{mg} /$ $\mathrm{L}$. Regarding lipid profile, total cholesterol levels of over $200 \mathrm{~g} / \mathrm{dL}$ and triglycerides with values above $150 \mathrm{mg} / \mathrm{dL}$ were recorded.

In our study resulted a predominance of territorial type of ischemic stroke (64\%) highlighted on CT/MRI imaging (fig.1).

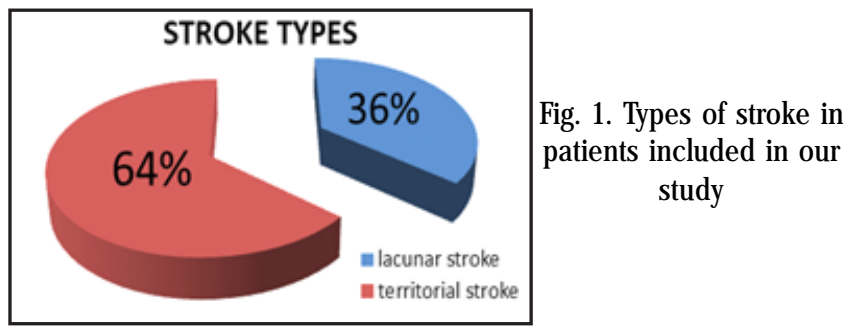

The group was divided into 5 age groups: $45-54$ years, 55-64 years, $65-74$ years, $75-84$ years and $85-95$ years. The mean age of the patients enrolled in the study was 73.49 years, the 75-84 age group presenting the highest risk of ischemic stroke and representing almost half of the cases, followed by the $65-74$ ages, which is suggestive of the fact that approximately $3 / 4$ of stroke cases occur after the age of 65 .

In our study female patients (61\%) were found to be more affected compared to male patients.

CPR was determined in all patients. $21 \%$ of patients had normal CPR values (values between $0-5 \mathrm{mg} / \mathrm{L}$ ), $79 \%$ of patients had elevated CPR values, $56 \%$ of patients had CPR values ranging from 5 to $50 \mathrm{mg} / \mathrm{L}$ and $23 \%$ of patients had CPR values above $50 \mathrm{mg} / \mathrm{L}$ (fig.2).

Over half of the cases reported showed CPR values ranging from $5-50 \mathrm{mg} / \mathrm{L}$, which means a moderate increase in marker level.

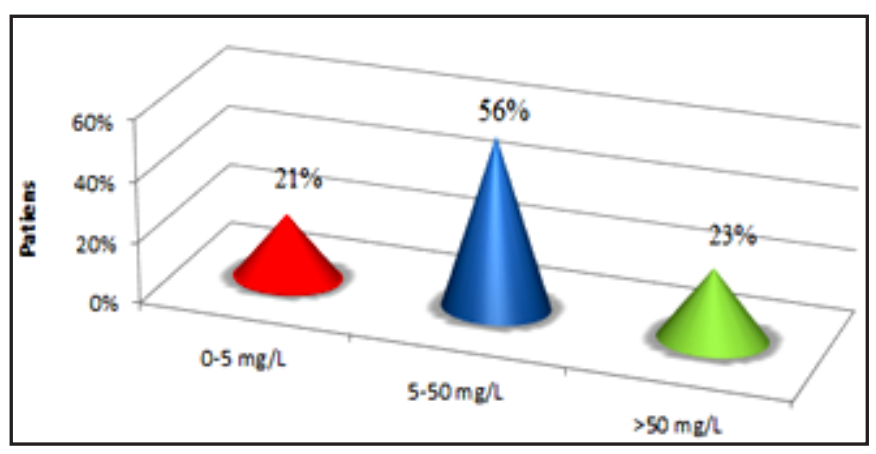

Fig. 2. CPR values found in the patients included in the study 
In the studied group, it was monitored the evolution of CPR values according to stroke type (fig. 3). It was observed an equalization tendency for the normal values of CRP for both types of stroke (lacunar-11\%, territorial-10\%). CPR values above $50 \mathrm{mg} / \mathrm{L}$ were found in patients with territorial stroke (15\%).

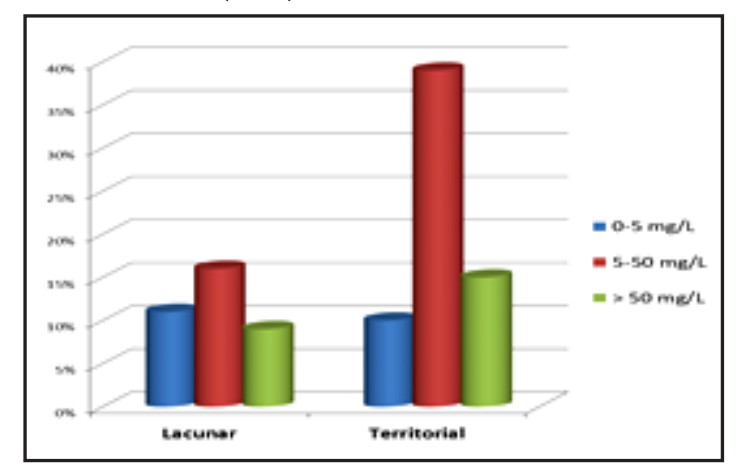

Fig. 3. Distribution of CRP levels by type of stroke

The degree of motor impairment measured by the mRC scale was assessed in all patients enrolled in the study. There were no significant differences in the cases studied between patients with severe impairment and patients with moderate impairment (fig. 4).

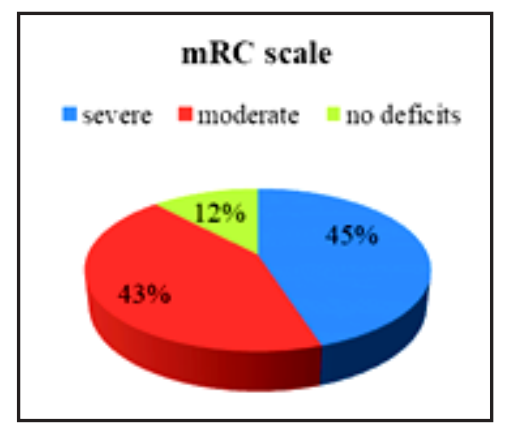

Fig. 4. Distribution of the motor deficit in the patients included in the study

The motor deficit related to the two types of stroke was divided into three categories: severe, moderate and no deficit. $9 \%$ of patients with lacunar stroke experienced a severe motor deficit, $20 \%$ moderate motor deficit, and $7 \%$ of patients had no motor deficit (fig. 5).

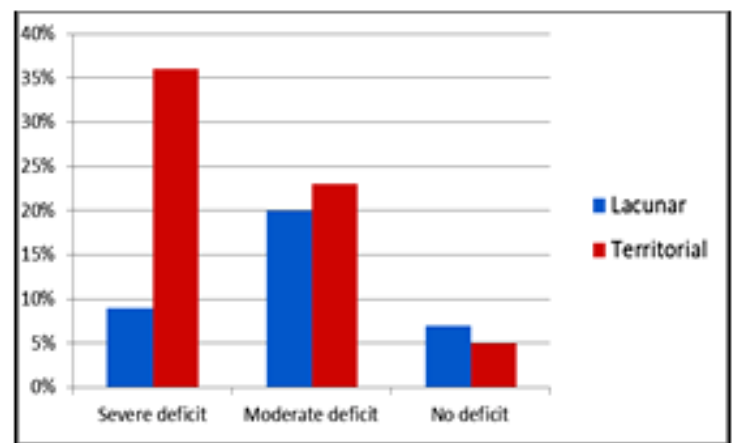

Fig. 5. The distribution of motor deficit reported to the two types of stroke

Regarding patients with territorial stroke, $36 \%$ had a severe motor deficit, $23 \%$ moderate motor deficit and $12 \%$ had no-motor deficit. It was found a high frequency of a severe motor deficit for the territorial stroke type, while for the moderate degree the distribution is approximately equal for both categories, with statistically significant value, $p=0.016$.

After assessing the severity of the motor deficit, the motor impairmentwas evaluated based on the CPR values. It is noticeable that predominate the moderate motor deficits, with CPR values ranging from $5-50 \mathrm{mg} / \mathrm{L}$. Severe motor deficit was predominant in patients with normal and above $50 \mathrm{mg} / \mathrm{L}$ CPR values (fig. 6).

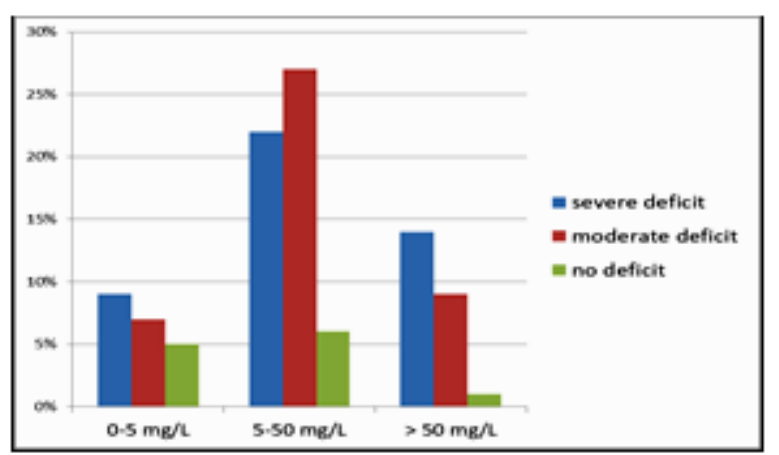

Fig. 6. The distribution of severity of motor deficits for different levels of CRP

The most important risk factors present in the patients included in our study were hypertension and atherosclerosis (fig. 7). Correlations were made between these risk factors and the CPR values. In most patients with these two risk factors were recorded mean CPR values (5-50 mg/L).

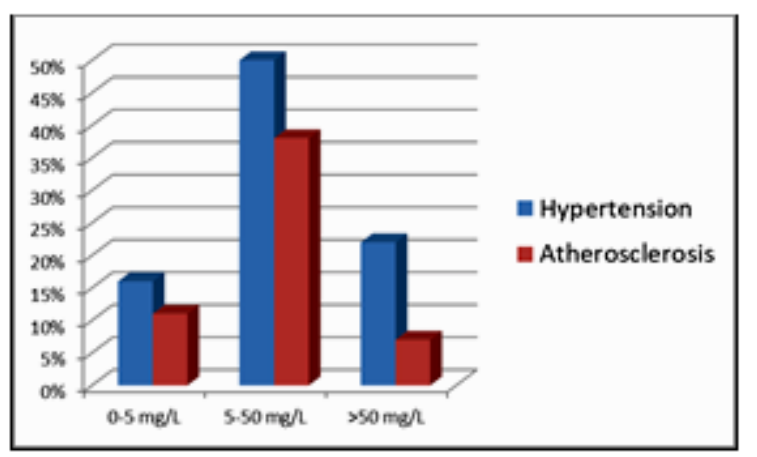

Fig. 7. Correlation of CRP values with hypertension and atherosclerosis

Correlations were also made between the CPR values and the risk of death. The highest death rate was seen in patients who had the highest levels of CPR (above $50 \mathrm{mg}$ / L). Patients who had CPR values between $5-50 \mathrm{mg} / \mathrm{L}$ had a lower death rate $(6 \%)$ and those who had normal CPR values had a death rate of $1 \%$. The prevalence of deaths in patients with CRP values above $50 \mathrm{mg} / \mathrm{L}$ is statistically significant $(p=0.04)$.

Even though it has been shown that the inflammatory process at the cerebral level in acute ischemic stroke is not as severe as in infections, in our study the prevalence of PCR values being between $5-50 \mathrm{mg} / \mathrm{L}$, however, the death rate was the highest at the highest values of the marker. The CRP is a non-specific inflammatory biomarker correlated with the prognosis and severity of ischemic stroke (fig. 8).

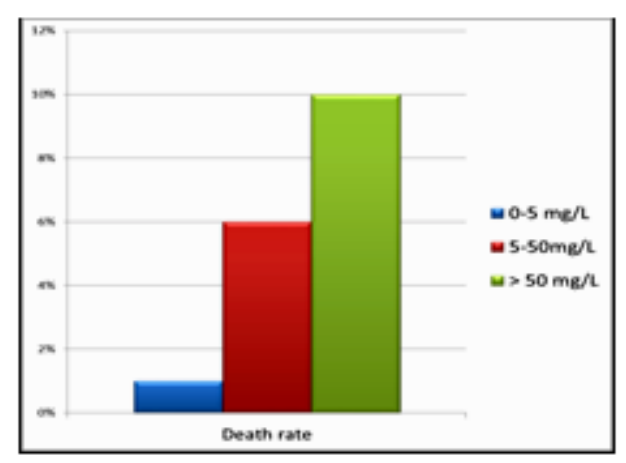

Fig. 8. Incidence of mortality based on CRP values

A meta-analysis that included 5 studies with plain inclusion criteria (neuroimaging to confirm ischemic stroke diagnosis, high-sensitivity CRP assay, and a 
functional outcome scale to assess prognosis beyond 30 days after stroke) concluded that there isa significant association between elevated baseline high sensitivity CRP and unfavorable long-term functional outcome [22].

Twelve studies involving 2269 strokes, of which 2436 were ischemic and 655 were hemorrhagic, were identified from 66,560 participants, included in a meta-analysis. When comparing the highest with the lowest hs-CRP category, the pooled RR of ischemic strokes was $1.46(95 \% \mathrm{Cl} 1.27$ $1.67)$ in a fixed-effect model. The pooled RRs of all strokes and hemorrhagic stroke were 1.23 (95\% Cl: 0.997-1.51) and $0.82(95 \% \mathrm{Cl} 0.59-1.13)$, respectively [23].

\section{Conclusions}

Stroke, in all its forms, is a real public health problem with its high frequency, serious or even fatal complications, and high costs.

In our study, we attempted an approach to the evaluation of the inflammatory process by means of the non-specific marker of inflammation-CRP in order to monitor and establish a prognostic in patients who had an acute ischemic stroke.

In conclusion, inflammation plays a crucial role in the pathogenesis of ischemic stroke; its complex mechanism involving several inflammatory mediators and inflammatory cells remains elusive. Further understanding of itmay provide new ideas in the prevention and treatment of ischemic stroke.

Acknowledgements: This study, being a retrospective one, did not require a written consent from the patients involved. The authors declare no conflict of interests and no sponsorship. All authors have read and approved this publication and had equal scientific contribution in publishing this material.

\section{References}

1.SIMATS, A., GARCIA-BERROCOSO, T., MONTANER, J., Biochimica et Biophysica Acta, 1862, No. 3, 2016, p. 411.

2.MUSUKA, T.D., WILTON, S.B., TRABOULSI, M., HILL, M.D, 187, CMAJ, No. 12, 2015, p. 887.

3.MOISEI, A., GLIGOR, F.G., BOJITA, M, CHIS, A., TOTAN, M, VONICAGLIGOR, L.A., CIURBA, A., Farmacia, 62, No. 6, 2014, p. 1239.

4.J OHNSTON, S.C., AMARENCO, P., ALBERS, G.W., DENISON, H., EASTON, J.D., EVANS, S.R., et al., The New England Journal of Medicine, 375, No. 1, 2016, p. 35.
5.CIAVOI, G., TIRB, A., BECHIR, E.S., BECHIR, F., SUCIU, I., Rev. Chim. (Bucharest), 69, no.10, 2018, p. 2648-2651

6.W ORRALL, B.B., BROTT, T.G., BROWN, R.D., BROWN, W.M., RICHS, S., AREPALLI, S., et al., J Neurol Neurosurg Psychiatry, 38, No. 4, 2007, p.1189.

7.SARWAR. N., BUTTERWORTH, A.S., et al., Lancet, 379, (9822), 2012, p. 1205-13.

8.AMMIRATI, E., MORONI, F., PEDROTTI, P. et al., Frontiers in Immunology, 5, No. 2014, p. 399.

9.MARNANE, M., MERWICK, A., SHEEHAN, O.C., HANNON, N., FORAN, P., GRANT, T., et al., Annals of Neurology, 71, No. 5, 2012, p. 709.

10.MULLER, H.F.G., VIACCOZ, A., FISCH, L., BONVIN, C., LOVBLAD, K.O., RATIB, O., et al. Stroke, 45(12), 2014, p. 3561-6.

11.REDGRAVE, J.N., LOVETT, J.K., GALLAGHER, P.J ., ROTHWELL, P.M., Circulation, 113, No. 19, 2006, p. 2320.

12.DEB, P., SHARMA, S., HASSAN, K.M., Pathophysiology, 17, 2010, p. 197.

13.SILISTEANUS, C., ANTONESCU, E., SZAKACS, J., TOTAN, M., ROMANFILIP, C., SERBB, H., CERNUSCA-MITARIU, M., GRIGORE, N., CERNUSCA-MITARIUS, I., Rev. Chim. (Bucharest), 68, no. 6, 2017, p. 1306-1309.

14.TILINCA, M.C., BARABAS-HAJDU, E., TUSA FERENCZ, G., NEMESNAGY, E., Rev Romana Med Lab, 26 (3), 2018, p.359-372.

15.IEMOLO, F., SANZARO, E., DURO, G., GIORDANO, A., PACIARONI, M., Immun Ageing. 13, No. 19, 2016, p. 1-6

16.*** https://www.uptodate.com/contents/acute-phase-reactants 17.VANGLIDER, R.L., DAVIDOV, D.M., STINEHART, K.R., HUBER, J.D., TURNER, R.C., WILSON, K.S. et al,. J Clin Neurosci, 21, No. 4, 2014, p.547-553.

18.IACOB, A., SIN, A., MOCAN, S., ORMENISAN, A., COMANEANU, R.M., HANCU, V., FULOP, E., TILINCA, M., Rev.Chim, 67, no. 10, 2016, p. 2022-2027.

19.SAMASCA, G., SUR, G., LUPAN, I., TILINCA, M., DELEANU, D., Centr Eur J Immunol,, 39 (3), 2014, p. 396-399

20.ROMAN-FILIP, C., GLIGOR, F., UNGUREANU, A., PRODAN, L., Farmacia, 61, No. 4, 2013, p. 742-747.

21.UNGUREANU, A., RUS, L.L., GLIGOR, F., LAZAROAE, A., PRODAN, L., ROMAN-FILIP, C., Farmacia, 64, 2016, No.4, p.507-511.

22.ZHOU, Y., HAN, W., GONG, D., MAN, C., FAN, Y., Clin Chim Acta. 2016, No. 30, p.453.

23.VANGLIDER, R.L., DAVIDOV, D. M., STINEHART, K.R., et al., J Clin Neurosc, 21, No. 4, 2014, p.547-543.

$\overline{\text { Manuscript received: } 17.10 .2018}$ 